Slavica

bruxellensia

\section{Slavica bruxellensia}

Revue polyphonique de littérature, culture et histoire

slaves

$2 \mid 2009$

Femme(s)

\title{
Anna Wieczorkiewicz, Apetyt turysty
}

\section{Grzegorz Czerwiński}

Traducteur : Dorota Walczak

\section{(2) OpenEdition}

\section{Journals}

Édition électronique

URL : http://journals.openedition.org/slavica/185

DOI : $10.4000 /$ slavica. 185

ISSN : 2034-6395

Éditeur

Université libre de Bruxelles - ULB

Édition imprimée

Pagination : 69

ISSN : 2031-7654

Référence électronique

Grzegorz Czerwiński, «Anna Wieczorkiewicz, Apetyt turysty », Slavica bruxellensia [En ligne], 2 | 2009, mis en ligne le 15 février 2009, consulté le 22 septembre 2020. URL : http://journals.openedition.org/ slavica/185; DOI : https://doi.org/10.4000/slavica.185

Ce document a été généré automatiquement le 22 septembre 2020.

\section{c) (7) $\Theta$}

Les contenus de Slavica bruxellensia sont mis à disposition selon les termes de la Licence Creative Commons Attribution - Pas d'Utilisation Commerciale - Pas de Modification 3.0 France. 


\section{Anna Wieczorkiewicz, Apetyt turysty}

\section{Grzegorz Czerwiński}

Traduction : Dorota Walczak

\section{RÉFÉRENCE}

Anna Wieczorkiewicz, Apetyt turysty, Universitas, Cracovie, 2008, 384 p.

NOTE DE L'ÉDITEUR

La langue originelle de cette recension est le polonais 
1 Cet ouvrage traite des aspects de la création culturelle dans le cadre du tourisme. L'auteur de l'ouvrage tente de répondre aux questions suivantes: Que cherchent les touristes contemporains pendant leurs voyages? S'agit-il seulement de visiter de beaux lieux et d'acquérir des impressions nouvelles? Ou y a-t-il là aussi une place pour une réflexion sur le fait même de vivre le voyage?

2 L'écrivaine consacre une place importante à la problématique de la recherche d'authenticité (de l'utopie sociale et de "l'ordre naturel» dans la conception rousseauiste). Elle la considère comme un élément constitutif du tourisme contemporain. Elle montre la tendance qu'ont les touristes à expérimenter tout ce qui est "non touristique " ou à dépasser les "frontières du spectacle", qui sont en quelque sorte les attractions touristiques offertes par les agences de voyage (c'est le phénomène de « la mise en scène de l'authenticité »).

3 L'auteur mentionne également la transformation des cultures ethniques sous l'influence de l'invasion d'une grande quantité de visiteurs ou l'incorporation de l'art local dans la sphère des biens et des services pour les touristes. La chercheuse s'intéresse à l'iconographie touristique, au processus de formation des mythes contemporains (tels que Barthes les comprenait). Elle soumet à l'analyse la littérature de voyage, des films, des publicités des agences de voyage, elle fait connaître au lecteur polonais les ouvrages de référence (surtout anglophones) dans ce domaine.

4 Ce livre mérite d'être recommandé. Il est dommage cependant que l'auteur n'ait pas soulevé l'influence du reportage de voyage (Ryszard Kapuściński, Wojciech Jagielski) sur le tourisme alternatif, très en vogue. L'analyse de notes de voyage prises par le tout un chacun, publiées entre autres sur des blogs, pourrait dévoiler de nouveaux aspects du tourisme contemporain.

\section{INDEX}

Index géographique : Pologne 
AUTEURS

GRZEGORZ CZERWIŃSKI

Université de Gdańsk 